E3S Web of Conferences 1, 20006 (2013)

DOI: $10.1051 / \mathrm{e} 3$ sconf/20130120006

(c) Owned by the authors, published by EDP Sciences, 2013

\title{
Analysis of trace elements in airborne particulate matters collected in Ankara, Turkey by TXRF
}

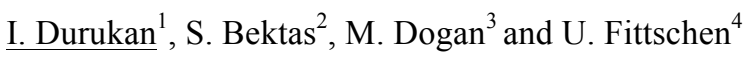 \\ ${ }^{1}$ Department of Chemistry, Hacettepe University, Ankara, TURKEY, ilknurt@hacettepe.edu.tr \\ ${ }^{2}$ Department of Chemistry, Hacettepe University, Ankara, TURKEY, fsbektas@hacettepe.edu.tr \\ ${ }^{3}$ Department of Chemistry, Hacettepe University, Ankara, TURKEY, dogan@hacettepe.edu.tr \\ ${ }^{4}$ Department of Chemistry, University of Hamburg, Hamburg, GERMANY, ursula.fittschen@chemie.uni-hamburg.de
}

\begin{abstract}
The main focus point of the presented study was the assessment of atmospheric burden of particulate matter and toxic trace metals in the atmosphere of Ankara, Turkey. For this purpose, outdoor samplings were accomplished in the capital city, Ankara. The types of filters, sample collection and sample preparation methods were investigated and optimized. Analyses were provided by the total reflection X-ray fluorescence (TXRF) spectroscopic technique in Germany. Spatial and temporal variations of air particulate matter (APM) levels in the city were examined. In some stations, APM sampled in according to their size distribution such as PM10 and PM2.5. Elemental characterization of size distributed PM were achieved and evaluated. It was detected that the elements mainly originated from soil in Beytepe station, from soil and solid fuel usage in Kayas station and from traffic and a variety of human activities in Sihhiye station in air samplings. While the elements of natural origin observed in PM10 fraction, the elements from traffic and human activities were in PM2.5. Eventually, enrichment calculations were performed in order to identify the pollution sources.
\end{abstract}

Key words: Air particulate matters, spectrometric method, TXRF, air pollution, PM10, PM2.5.

\section{Introduction}

Efficient control of air quality and related health effects requires a comprehensive understanding of the identity of atmospheric hazardous pollutants. Without this understanding, the introduction of new laws, regulations, and technical devices for environmental protection will be not possible or ineffective.

By reason of the fast growth in the population and increasing number of vehicles in traffic, Turkey has faced with increasing air pollution related problems. Because of that, effectively monitoring is necessary for air quality control. Especially in the last quarter of the 20th century, numbered persuasive research and studies to measure the danger level of air pollution to risk healthy life in almost all of the cities of Turkey were performed. Ankara, like most of the large urban centers in Turkey, suffered rapid urbanization in the last 30 years. Population increased very rapidly between the years 1990 and 2000 due to migration from countryside. The number of motor vehicles in Ankara increased sharply from 370,000 in 1990 to 850,000 in 2003 as a result of population increase (TUIK, 2010). Since, the city faces increasing air pollution.
The main focus point of the presented study is the assessment of atmospheric burden of particulate matter and toxic trace metals in the atmosphere of Ankara. The study aimed to reveal the average atmospheric level of total suspended particulate matter (TSP), PM10, and PM2.5 for different regions of Ankara. It was planned to give place to comparison studies of sampling filters and determination of the appropriate method of sample preparation. In that way, it was able to test the parameters that may affect the results in the sampling steps. In addition, it was intended to make quantitative evaluation of the content of the outdoor Ankara samplings by spectrometric method total reflection X-ray fluorescence (TXRF) is applying to nearly ninety percent of contained elements of a variety of micro samples simultaneously and fast. Spatial and temporal variations of TSP, PM10, PM2.5 and elemental levels were in the planned studies. By the enrichment calculation, it was planned to identify the pollution sources. It is believed that the present study would be of great significance in raising awareness about the current ambient air pollution in Ankara.

\section{Materials and Methods}


Total suspended particulate (TSP) samplings were performed in many stations (Sihhiye, Ulus, Mamak, Sincan, Keçiören, Bahçelievler, Dikmen and Demetevler) in Ankara especially where there is very heavy vehicle and human traffic. Since it was possible to get only TSP in these eight stations, additional particulate matter (PM) samplings were needed. They were performed in Kayaş, Sihhiye and Beytepe; PM10 and PM2.5 particulate sizes by Sierra model sampling system in order to perform size separation and characterization of chemical constitutes of airborne particulate matter (APM).

Two kinds of high volume samplers were used to collect air samples for the present investigation. While PM162M high volume sampler was used to collect total particulate matter (TPM), to collect PM10 and PM2.5 Sierra Andersen model high volume sampler was used. The particles are sampled by PM162M at constant flow rate and collected on filters for gravimetric weighing and possible chemical analysis. Whatman GF6 Glass Fiber filters with a diameter of $47 \mathrm{~mm}$ were used for aerosol collection. Glass fiber filters were used because of their high collection efficiency for all particle sizes (Lee, 1993). Sierra Andersen Model SAUV-10 H PM10 High-Volume air sampler (F\&J Specialty Products Inc., Florida) was employed to collect aerosol particles with stacked filter unit (SFU) which consists of two grease coated poly carbonate (Nuclepore) filters placed in series and preimpactor to remove particles in sizes of PM10 and PM2.5. Pore sizes of the top and bottom filters used in this study were 8 and $0.4 \mu \mathrm{m}$, respectively. Filters before and after sampling were kept in the stable conditions: temperature $\left(24.5 \pm 2{ }^{\circ} \mathrm{C}\right)$ and relative humidity $(34 \pm 3 \%)$ at least 24-h in desiccator box in Class-100 clean room.

The microwave oven used to digest samples was Model CEM MARS 5 (CEM Corporation). The collected samples were analyzed by TXRF instruments in Hamburg University, Germany. The analyses were performed with commercially available Atomika, EXTRA II (Rich. Seifert \& Co., Ahrensburg, Germany) and S2 PICOFOX trade mark TXRF spectrometers. EXTRA II is using a Mo x-tube, operated at $50 \mathrm{kV}$, and $38 \mathrm{~mA}$. The measurement time was equal to $1000 \mathrm{~s}$. In S2 PICOFOX, the X-ray tube is a metal-ceramic tube, which is air-cooled and equipped with an earthed cathode. The quartz sample holders were used during TXRF analysis.

\section{Results and Discussion}

\section{Filter media}

An important factor in obtaining a useful aerosol sample is the material on which it is collected. The filter should be retentive for particles but must be permeable for air flow. It should provide the aerosol sample ready to quantify both the total mass of the collected material and the chemical composition of the sample. The blank filters (glass fiber and polycarbonate membrane) were placed in sample holders of the particle collection systems and then removed without doing any sampling to obtain field blank values. Then, microwave leaching process was applied the filters and analyzed them by Picofox model TXRF. So the blank was a reagent + containers + empty filter + sampler (field) contamination. Comparisons of the average blank values were performed. The results show, the blank glass fiber filters have higher values of element concentration than polycarbonate membrane filters. The polycarbonate membrane filters are offered the better blank-free material although a few elements exhibited blank values as $\mathrm{Mg}>\mathrm{Cl}>\mathrm{Cr}>\mathrm{Zn}>\mathrm{Br}$. Since the membrane filters had lower blank concentration values, they are suitable for the quantitative analysis of trace elements. The difference in morphologic structures of the glass fiber and poly carbonate filters can be seen in Fig. 1. In glass fiber filters, particulate matters seem like embedded between the fibers, where as they are more attached to the surface in polycarbonate one.

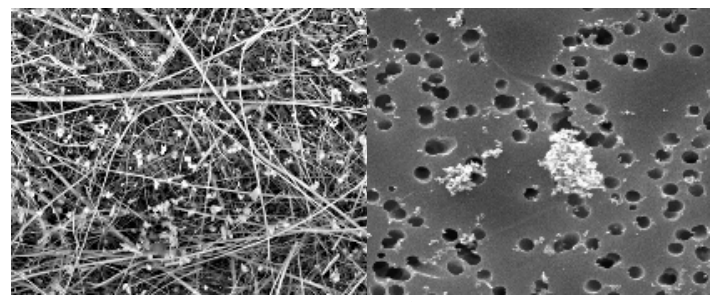

(a)

(b)

Fig. 1. SEM images of the sample loaded glass fiber filters of Kayaş-1 (100 fold magnification) (a) and sample loaded poly carbonate fine filter Beytepe 1 (3000 fold magnification, particle size $<2.5 \mu \mathrm{m}$ ) (b).

\section{Comparison of leaching procedures}

Three different wet leaching methodologies hot acid leaching (HAL), ultrasound assisted hot acid leaching (USHAL) and microwave leaching (MWL) were applied for sample preparation of atmospheric aerosols. In order to gauge the effectiveness of the leaching procedures, recovery studies were conducted using solutions prepared from NIST Standard Reference Material 1648a Urban Particulate Matter through all three proposed leaching procedures. A simple microwave leaching method using only $\mathrm{HNO}_{3} / \mathrm{H}_{2} \mathrm{O}_{2}$ gave good recoveries $(90 \%-106 \%)$ for all elements except $\mathrm{Cr}$ in SRM 1648a.

\section{Spatial and temporal variation of TSP}

The winter season was covered the months of December, January, and February whereas the summer season was covered June, July, and August. The amount of particulate matter is quite high for all the stations except Beytepe and Dikmen. In addition, the amount of PM10 in station Kayaş1 was exceeded to guideline values both in winter and summer periods. The guideline values for PM2.5 are $10 \mu \mathrm{g} / \mathrm{m} 3$ for WHO and $15 \mu \mathrm{g} / \mathrm{m} 3$ for EPA (annual), respectively. There is no guideline value of Turkish Ministry of Environment for PM2.5. While the amount of PM2.5 were below the guideline values in summer period, it was at limit value for Beytepe station and higher than guideline value for Kayaş1 station in winter. The levels of TSP in stations were varied between 35.01 to $175.51 \mu \mathrm{g} / \mathrm{m}^{3}$. Particulate matter in all sampling stations during winter season are higher than 
summer. Variations may be sourced from high concentrations of traffic-related pollutants during winter because the number of vehicles in traffic is approximately $25-30 \%$ smaller during the summer months (Ankara Municipality, unpublished data). Observed difference between stations was probably due to different contributions of space heating and traffic sources on these stations. For the season winter, the amount of TSP are in the order of Sihhiye $>$ Kayaş $>$ Ulus $>$ Bahçelievler $>$ Dikmen $>$ Beytepe. The order is like Sıhhiye $>$ Ulus $>$ Kayaş $>$ Bahçelievler $>$ Beytepe $>$ Dikmen for the season summer (Fig. 2). The highest level was observed in Sihhiye station for both summer and winter seasons. The reason could be that, the dominant impact on pollution and the amount of TSP should be traffic. In winter, the amount of TSP of the station in Kayaş was following the Sihhiye. However, this station is coming at third order for the season summer. This can be related that in winter, sources from combustion processes highly affecting the level of the particulate matter. So, the pollution coming from coal burning which is still used for heating in that region is highly predominant for the season winter. The lowest seasonal variation in the levels of TSP was observed in Beytepe station. This can be concluded that the pollutant sources are very weak and limited for this area. However, among all stations, the lowest level of TSP was observed for Beytepe in winter but in summer it was observed for Dikmen. The reason for higher TSP for Beytepe according to Dikmen in summer may be the unpaved and much more natural structure of Beytepe and re-suspension of soil dust in dry weathers. The high altitude of the spatial of Dikmen can lead better ventilation conditions that prevailed during the summer months and decrease in TSP level. The windy structure of Dikmen can be explained by continuous circulation of air due to the draft between Gölbaş1 Ankara. The stations of Bahçelievler and Ulus may be in the influence of traffic in both seasons.

\section{Elemental characterization of PM10 and PM2.5}

To determine how the content of elements in APM collected in different sizes, PM10 as coarse particle and PM2.5 as fine particle samplings were performed in three stations (Beytepe, Kayaş and Sihhiye). The samplings were performed in winter season. The elements Al, K, Ti, $\mathrm{Ca}, \mathrm{Cr}, \mathrm{Mn}, \mathrm{Fe}, \mathrm{Co}, \mathrm{Cu}, \mathrm{Sn}$ and $\mathrm{Ce}$ are loaded more in coarse sized particulate matter. While V, Ni, As, Br, Se, $\mathrm{Pd}, \mathrm{Cd}, \mathrm{Sb}, \mathrm{Hg}$ and $\mathrm{Pb}$ highly disturbed in fine ones. These data show the crustal and natural elements mostly loaded in large particulate sizes while the elements sourced from human activities mostly loaded in smaller sizes. The amounts of TSP in Beytepe were quite low. Generally, heavy toxic elements showed higher concentration in fine particulate matter than in coarse one. Since, monitoring of PM2.5 and identifying the chemical characterization are very important and necessary task. In Kayaş samplings, higher levels of elements were observed compared to Beytepe. There is not too much traffic load in this area. Since, the higher levels of the elements $\mathrm{Cd}$, As, $\mathrm{Se}, \mathrm{Cr}, \mathrm{Co}, \mathrm{Fe}, \mathrm{Ti}, \mathrm{V}$ may arise from the coal burning for hearting in winter season in this area. In Sihhiye station, the levels of all elements were quite higher than the other stations. The elements $\mathrm{Ti}, \mathrm{V}, \mathrm{Cr}, \mathrm{Ni}$, $\mathrm{As}, \mathrm{Se}, \mathrm{Pd}, \mathrm{Cd}, \mathrm{Sb}, \mathrm{Pt}, \mathrm{Br}, \mathrm{Hg}$ and $\mathrm{Pb}$ were highly loaded in fine fraction and this can be easily interpreted as these anthropogenic traffic related elements were in fine particulate matter at high percent. The elements $\mathrm{Mg}, \mathrm{K}$, $\mathrm{Ca}, \mathrm{Rb}$ and $\mathrm{S}$ were loaded in coarse fraction at higher percentage. These elements can be evaluated as terrestrial elements. In addition, for the some elements, generally sourced from natural sources and have high percent in coarse friction in Kayaş and Beytepe stations, the increase was observed in their levels in fine fraction and the percentages were nearly same even sometimes higher in fine one.

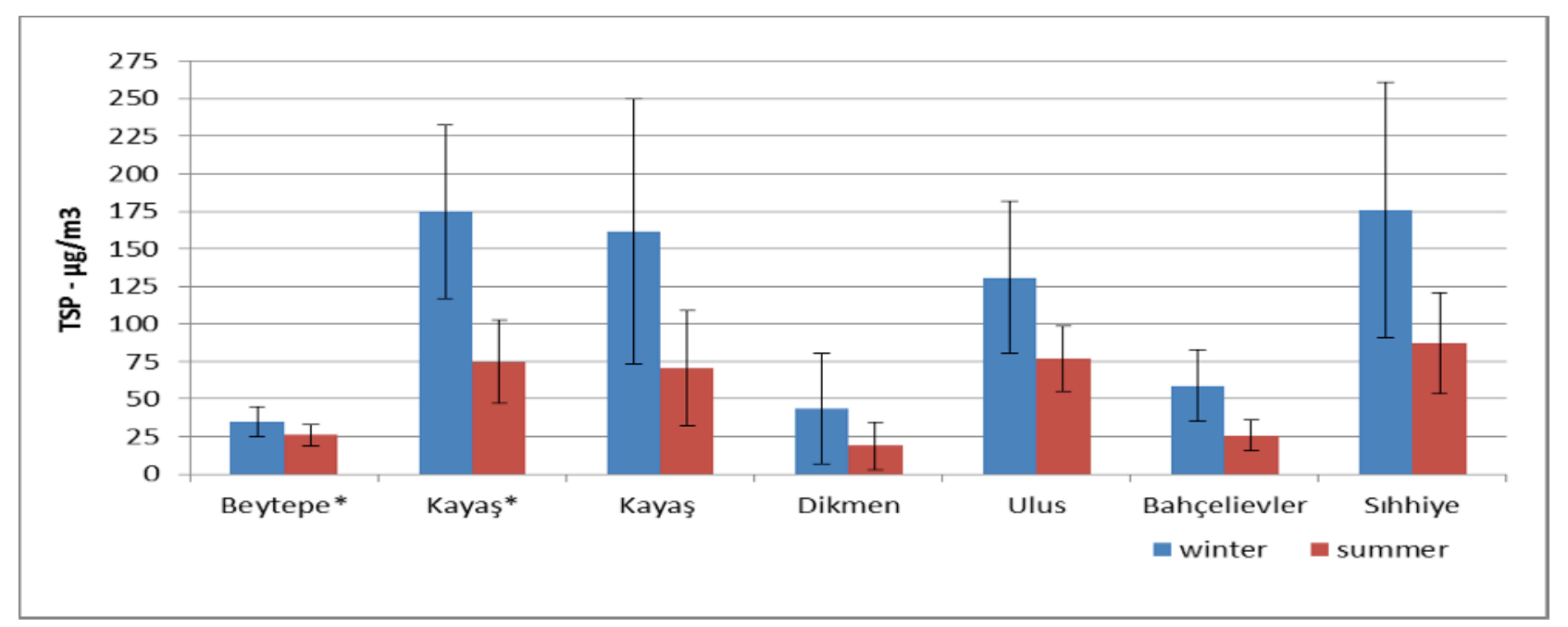

Fig. 2. The bar graph of the TSP values of the stations for summer and winter periods. (*PM2.5 and PM10 sampling were performed for these stations.) 
This situation can interpreted as these elements ( $\mathrm{Al}, \mathrm{Ti}$, $\mathrm{Mn}, \mathrm{Fe}, \mathrm{Co}, \mathrm{Zn}, \mathrm{Ba}, \mathrm{Sr}$ ) sourced from both natural and anthropogenic. The amount arising from anthropogenic sources led to an increase in their levels.

\section{Enrichment calculation}

One of the primary goals of this study was to provide information on the contribution of emission sources on measured pollutant concentrations. The minimum, maximum and the average elemental concentrations of the elements for the samples collected from Sihhiye in 2008 winter were determined. In the present section, to investigate the influences of the pollution sources on air particulates, the Enrichment Factors (EF) for some elements were calculated as below and theresults were evaluated.

$\mathrm{EF}=$ (Air conc. of indicated element / Air conc. of Al) / (Crustal conc. of indicated element / Crustal conc. of $\mathrm{Al})$.

The results indicated that the elements $\mathrm{Al}, \mathrm{K}, \mathrm{Ca}$, $\mathrm{Rb}, \mathrm{Mg}, \mathrm{Ba}$ and $\mathrm{Sr}$ originated from soil. The elements $\mathrm{Ti}$, $\mathrm{Mn}, \mathrm{Fe}$ and $\mathrm{Co}$ were from both crustal and anthropogenic sources. $\mathrm{Co}, \mathrm{V}$, and $\mathrm{Cr}$ were occurred from both residential heating and traffic. $\mathrm{Ni}, \mathrm{Cd}, \mathrm{Zn}$ might be originated due to fuel oil consumption. This case can be comment as both traffic and other human activities are effective on levels of them but the influence of the traffic should be dominant. The enrichment factors of the elements $\mathrm{As}, \mathrm{Se}, \mathrm{Pd}, \mathrm{Sb}, \mathrm{Pt}, \mathrm{Br}, \mathrm{Cu}$ and $\mathrm{Pb}$ were extremely high than the other ones. These can be interpreted as these might be mostly sourced from motor vehicles. The platinum group elements (PGEs) (Pd, Pt) contamination in populated areas increase due to the use of catalytic converters in automobiles. The huge amount of $\mathrm{Pd}$ and $\mathrm{Pt}$ in our Sihhiye samplings might be raised from this source. The ratio of $\mathrm{Cu} / \mathrm{Sb}$ in our study for Sihhiye sampling was 4.1 and was compatible with the fact that the $\mathrm{Cu} / \mathrm{Sb}$ ratios in brake linings are about 5 . Since, $\mathrm{Sb}$ and the elements in this same group have high
EFs should be sourced from mostly traffic.

\section{Conclusion}

Air suspended particle pollution has become a serious problem all around the world. Accurate determination of the chemical composition of air particulate matter is a difficult analytical task. The study reported in here aimed to evaluate the particulate matter for outdoor samplings by a spectrometric method TXRF.

TXRF was very successful in the determination of many elements in APM samples. Although it is appropriate for more number of elements, its capacity of determination is disable for Si (sample holder material), Mo or W (the x-ray sources), In or Ga (internal standards) and is very low for the elements when their main analysis lines overlap with these species. Sometimes it is difficult to perform analysis with high capacity for the elements have atomic number less than Si and even impossible for the elements Li, Be, B. Despite all these, TXRF could be highly suggested for the analysis of air samples collected in cities which are in the influence of traffic, industry, combustion etc., and especially for the determination of nearly 30 elements such as commonly analysis required Fe, Ni, Co, Cd, Cr, Zn, Cu, Mn, Pb, Pd, Pt, and elements like sourced from natural dust $\mathrm{K}, \mathrm{Ca}, \mathrm{Sr}, \mathrm{Ba}, \mathrm{Rb}, \mathrm{Ti}, \mathrm{Ag}$, $\mathrm{Au}, \mathrm{Al}$ and nonmetals such as $\mathrm{Cl}, \mathrm{Br}, \mathrm{S}, \mathrm{P}$, even $\mathrm{As}, \mathrm{Sb}$, $\mathrm{Bi}, \mathrm{Ga}, \mathrm{Ge}, \mathrm{Y}$ simultaneously in a short time. Determination of all these elements by TXRF is possible to make analysis at ppb level for APM samples.

\section{References}

Lee, K. W., Ramamurthi, M. Filter Collection. Aerosol Measurement. Principles, Techniques and Applications. edited by Van Nostrand Reinhold New York1993.

TUIK. "Adrese Dayali Nüfus Kayit Sistemi Veri Tabani." 2010. 